\title{
Nurses' Performance at the Family Planning Clinics in Alexandria
}

\author{
Walaa Khamis Abo El-Enen, Nurse Specialist \\ Obstetric and Gynecologic Nursing, Faculty of Nursing, Alexandria University \\ Sahar Anwar Rizk, Professor \\ Obstetric and Gynecologic Nursing, Faculty of Nursing, Alexandria University
}

\author{
Maha El-Habashy, Assistant Professor \\ Obstetric and Gynecologic Nursing, Faculty of Nursing, Alexandria University
}

\begin{abstract}
Everywhere it is recognized that nurses can make unique and useful contribution to family planning by performing a variety of tasks including initial assessment of client, counseling, services delivery, infection prevention and control, and also follow up. Good nursing performance in family planning clinics helps individuals and couples to meet their reproductive health needs safely and effectively. Thus, it can help for increasing family planning users and control morbidity, mortality rate and unplanned population growth. Objective: Assess nurses' performance at Family Planning Clinics in Alexandria. Setting: The study was conducted at 12 Family Planning Clinics; 4 Family Planning Clinics (FP) affiliated to 4 hospitals that randomly selected one from each health agency in Alexandria. The remaining 8 outpatient FP clinics, affiliated to Family Health centers that were randomly selected, one from each zone in Alexandria. Subjects: All nurses (100) working at the FP Clinics affiliated to the previously mentioned settings. Tool: Nurses' Performance Observational Checklist. Results: $94 \%$ of study nurses had fair score of performance in family planning clinics. The rest (6\%) \& none of them had good as well as poor total score of performance respectively. Study findings also show that, there was a statistically significant positive correlation between attending training programs about family planning and level of nurses' performance. There was no statistically significant correlation between total score of nurses' performances and their Socio demographic characteristics as: age, marital status, level of education and occupation of the recruited subject. Conclusion: In all study setting the majority of study nurses had fair total score of performance regarding F.P clinics, while the rest $6 \%$ of the recruited nurses had good score of performance and none of them had poor score of their performance in family planning clinics. Nurses' performance has positive significant relation between received training programs about family planning and their performance in family planning clinics. Recommendations: Clear job description should be made for nurses in family planning clinics and review regularly and update as necessary. There is an urgent need to design periodic educational training programs to improve knowledge, skills of nurses about family planning care as well as to improve their performance.
\end{abstract}

Keywords: Nurses' performance; Family planning.

\section{Introduction}

Population growth is a major challenge in most developing countries. currently the world population is growing by over 80 million people every year (July 2018), the current world population is 7.8 billion according United Nations estimates (2025) the world will contain over 8 billion people $^{(1,2)}$. Egypt's population is growing at an explosive rate. Data from the UN's 2017 World Population Prospects Report estimates that Egypt's current population is approximately 97 million. In July 2018 the population had risen to 99.4 million $^{(2,3)}$.

To overcome the problem of overpopulation, the family planning program in Egypt had started as early as February 1966. It aimed to help families to have a suitable number of children, help mothers to have pregnancies within the safest childbearing period, and postpone pregnancy for a required period of time, when indicated, for medical and social purposes ${ }^{(4)}$. 
According to World Health Organization family planning is defined as "the ability of individuals and couples to anticipate and attain their desired number of children and the spacing and timing of their births. It is achieved through use of contraceptive methods and the treatment of involuntary infertility, while contraception is any method by which pregnancy is prevented $^{(5)}$.

Family planning saves the lives of women and children by helping them to avoid unsafe abortion, limiting the risk of pregnancy and childbirth, reducing the number of births, and limiting pregnancy to the healthiest ages ${ }^{(5,6,7)}$.

Family panning can be broadly classified as natural and modern (artificial). Modern contraceptive methods include the Hormonal contraception methods (i.e. Oral contraceptives, injectable, implants and patches); the Intra-uterine device (IUD); barrier methods (the male and female condom, diaphragm, cervical cap, spermicidal and permanent methods(tubal litigation and vasectomy) The natural methods include standard days (Calendar or beads); abstinence; withdrawal and Lactational Amenorrhea (LAM) ${ }^{(8)}$.

Nurses constitute the largest human resource element in healthcare organizations, and form the backbone of the health system in the public health sector and their performances have a direct effect on quality of health care, so that the country relies heavily on nurses for service delivery; their performance is critical for the successful provision of health care productivity $^{(9)}$. In addition to nurses play a key role in the promotion of women's reproductive health. So, assessment of health care workers performance is crucial, it closely links with the productivity and quality of care provision within health care organizations $^{(10)}$.

Nurses' performance appraisal is periodic formal evaluation of how well the nurse has performed her duties during specific period using services indicator and providing feedback to the employee ${ }^{(10)}$. The assessment of the nurses' performance in providing family planning services is an important approach to determine professional competence, enhance staff development, motivate them toward higher achievement, improve communication between managers and personnel and encourage relationships among nurses, determine training and developmental needs of nurses, select qualified nurses for advancement and salary increases. Observation is the common method for measuring the staff performance ${ }^{(11)}$.

\section{Aim of the Study}

Assess nurses' performance at family planning clinics in Alexandria.

\section{Research Question}

What is the level of nurses' performance at family planning clinics in Alexandria?

\section{Materials and Method}

\section{Materials}

Design: A pure descriptive research design was utilized in this study.

Setting: The study was conducted at 12 Family Planning Clinics; affiliated to the different available health agencies in Alexandria Governorate 4 Family Planning Clinics (FP) affiliated to 4 hospitals that was randomly selected one from each health organizations .namely: EL-Shatby Maternity university Hospital, El-Gomhorea Hospital, Faisal Center, Dar El-Welada Hospital (Maternitee) The remaining 8 outpatient FP clinics, affiliated to Family Health centers that was randomly selected, one from each zone in Alexandria as follow: Smouha Family Health Center, El-Amoud Family Health Center, El-Amrawy Family Health Center, El-Hadaraa Keble Family Health Center, El-Mansheia 1 Family Health Center, El-Agamy Family Health Center, El- 
Ameriya Family Health Center and Baheg Family Health Center.

Subjects: All nurses (100) working at the previously mentioned settings and providing family planning services for women.

\section{Tool:}

\section{Nurses' Performance Observational Checklist}

It was adapted from the Ministry of Health guidelines in Egypt ${ }^{(32)}$, and utilized by researcher to collect the necessary data it entailed two parts:

Part I: Socio-demographic data: It was developed by the researcher to collect data about the study subjects which included: age, marital status, level of education, position, and years of experience and attendance of FP training programs.

Part II: Nurses' Performance Observational Checklist: It consisted of 36 items distributed among 5 dimensions as follows:

- Initial Assessment (3 items)

- Counseling (6 items (GATHER technique)

- Assisting in IUD insertion (20 items)

- Infection Prevention and Control (4 items)

- follow up (3 items)

Each procedure item was given a score as follows: done correctly and completely (3), done correctly but not completely (2) not done (1). The total score of nurses' performances will range between 36-108.

Nurses' performance was ranked as follows:

- Poor for a total score $-<60$.

- Fair for a total score 60 - 84.

- Good for a total score $\geq 85$.

\section{Method}

- Permission from Faculty of Nursing, University of Alexandria was directed to the responsible authorities of the previously mentioned study settings then permission from ministry of health and population in Cairo was obtained as well as the director of health care centers and permission from Health Insurance Organization in Cairo governorate.

- Tool was adapted from the Ministry of Health guidelines in Egypt for initial and return visit and tool content validity was tested by a jury of five experts in the field of obstetric and gynecologic nursing. The recommended modifications were done and the final form was finalized after proving valid. Tools reliability were accomplished by CRONBACH'S ALPHA test and the result was statistically acceptable $(\mathrm{r}=0.85)$.

- A pilot study was conducted on 10 nurses from the previously mentioned centers working at clinic other than FP clinic.

- Data was collected by using observational checklist for each nurse twice for each Procedure.

- Data was collected over a period of 6 months started from the beginning of august 2018 till the end of February 2019. The number of nurse's observational checklist per day was 23 nurses in each clinic. Two days per week.

\section{Ethical considerations:}

For each recruited subject, the following issues will be considered: Witness consent from hospital authority after explanation of research purpose, keep anonymity, keeping their privacy and right to withdraw at any time as well as assuring confidentiality of their data.

\section{Statistical Analysis}

- The collected data was revised, categorized, coded, computerized, tabulated and analyzed using IBM statistical package for social sciences 
(SPSS) software package version 20.0 .

- Qualitative data were described using number and percent. Quantitative data were described using mean, standard deviation. Significance of the obtained results was judged at the $5 \%$ level.

\section{Results}

Figure (1) reflects the total score of the studied nurses' performance. The vast majority of study nurses $94 \%$ had fair total score of performance at family planning clinics, and only $6 \% \&$ none of them had good and/ or poor total score of performance respectively.

Table (1) demonstrates number and percent distribution of the study nurses according to their performance during initial assessment. It was observed that all of them prepared environment of clinic completely as: ensure good ventilation and cleanness of the clinic and availability of equipment and supplies however, $70 \%$ and $87 \%$ Prepare visual aids facilities and available contraceptive methods correct and complete Regarding history taken it was observed that all the nurses had taken personal and social history correct and complete, as well as $70 \%, 76 \%, 90 \%$ of them took family history, obstetric history, and previously used FP methods in correct and complete manner respectively. While, 43\%, 50\% of nurses took gynecological medical and surgical history correct but incomplete respectively. Approximately one- half $(49 \%)$ of them neglect Breast feeding history.

Regarding nursing role as assistance in physical examination, all $\& 99 \%$ of them did not measure vital signs except blood pressure and/or woman' height. Furthermore, all of them $100 \%$ didn't assist in palpation of thyroid gland, abdomen and lower extremities and also, not assist in auscultation of heart sound, however only $4 \%$ of nurses did inspection of face correct but incomplete.
Table (2) Shows number and percent distribution of the study nurses according to their role in counseling session .it was observed that the vast majority of nurses 99\% asked the client about the preferred method, more than one-half (54\%) didn't tell The client about different birth spacing methods ,less than two-thirds (62\%) didn't help the client to choose the best method, approximately all of them $98 \%$ \& $92 \%$ didn't explain to them the method chosen but they determine the date of return visit correct and complete.

Table (3) shows number and percent distribution of the study nurses according to their Assistant role in IUD insertion. It was observed that before insertion all study nurses sterilized the instruments and prepared equipment's correctly and completely. Almost 99\%, 95\% and 95\% of them Record client data, ensure client privacy and fixed the light source in place correctly and in complete manner respectively. On the other hand, counseling about IUD not provided for $82 \%$ of the clients. While, $94 \%$ \&95\% \& $89 \%$ of them didn't explain the procedure, or tell the client the expected discomfort during some of the steps and didn't ask client to empty her bladder before the procedure, or even wash her hand respectively, but more than two-thirds $(66 \%)$ wear gloves.

During insertion all study nurses didn't report the provider with the results of general physical examination or assisted in assessment of client's genitalia. only more than one-quarter $(27 \%)$ of them assist the provider during the steps of IUD insertion.

After insertion only $7 \%$ of them let client wait in clinic for 15 minutes after insertion. The vast majority of them (98\%) immersed the used instruments in antiseptic solution and registered date of insertion in the client's record and give her special card. In addition, less than four-fifth $(78 \%)$ of them didn't give the client the post insertion instructions of IUD. Compared to one-half $(50 \%)$ of them removed the gloves and wash their hands. 
Table (4) delineates number and percent distribution of the study nurses according to infection prevention and control in FP room. Regarding hand washing procedure, $100 \% 99 \%, 98 \%$ and $87 \%$ of nurses were wetting their hands and dispensing about 5 $\mathrm{ml}$ of liquid soap or disinfectant into the palm of the hand, rubbing hands palm to palm, rinsing hand with clean water and drying hands with towel completely and correctly respectively. While, $58 \%$ \& $75 \%$ $\$ 83 \%$ didn't remove jewelry before hand washing, not rub right palm over left dorsum with interlace fingers, and not rub palm to palm with interlace fingers respectively. However approximately all of them $99 \%, 100 \%$ neither rotational rubbing of left thumb clasped of right palm nor backward and forward to clasped finger.

Regarding their performance in cleaning $\&$ disinfection of equipment a $98 \%$ \& $100 \%$ of study nurses soaked the instrument in tab water containing detergent, scrubbed instrument vigorously, rinsed instrument with clean water and disinfected of equipment by using alcohol or chlorine in correct and complete manner. However, approximately three quarter $(74 \%)$ of them neglected wearing heavy utility rubber gloves.

Regarding performance in sterilization of instrument, all of study nurses follow the recommendation of sterilization correctly and completely in some aspects as: ensured that all instruments clean and dry placed instruments in the oven and heat the holding oven temperature $180 \mathrm{c}^{\circ}$ for 30 minutes or $170 c^{\circ}$ for one hour. However, $42 \%$ of them didn't wrap the instrument with foil or place them on tray.

Regarding performance in safety precaution taken while giving injection. It was observed that all of them done correct and completely recommendation of giving injection as used disposable syringes during IM injection, not recap needles and place needle in puncture resistant sharp box. However, most of them $93 \%$ didn't wear disposable gloves during injection.
Table (5) reveals number and percent distribution of the study nurses about their role in follow up of client at FP clinic. Regarding return visit, $89 \% \& 92 \%$ of the study nurses didn't measure vital signs or weight compared to $38 \%$ who referred the needed case correctly and completely. Approximately most of them $99 \%$ renewed the supplies of contraceptive methods and determined the date of next visit and registered correct and complete information in client card. Regarding follow up of clinic, all of them revised the amounts of stock and types of contraceptive methods and prepared request for getting contraceptive methods from storage. Documentation approximately all of them 99\%, 93\% registered all client data accurate and complete and kept all records clean and tidy. More than four -fifth (83\%) didn't take informed consent from client about chosen method. and about two-thirds $(66 \%)$ of them prepared periodic reports about stock of contraceptive methods in the clinic. Respectively on the other documentation less than three-fifth $(58 \%)$ of them didn't prepare monthly report and quarter year report about clinic activity.

Table (6) denotes the relationship between socio demographic characteristics of nurses and total level of nurses' performance that there isn't statistically significant correlation between total level of nurses' performance and their Socio demographic characteristics as: age, marital status, level of education and occupation.

Table (7) relationship between level of nurses' performance and participation of in family planning programs illustrates that there was a statistically significant positive correlation between attending training program about family planning and level of nurses' performance $(\mathrm{MCP}=0.008$, $\mathrm{FEP}=1.000)$.

\section{Discussion}

Family planning service is a unique in providing the mean for couples to space or limit their births as well as to stabilize 
world's population . They also have a role of reducing material mortality ratio as well as rates of infant and child morbidity and mortality it is promoting individual and family health and well-being. However family planning varies according to religion or cultural values, myths, knowledge, effectiveness of the method, sex, age policies, social and economic factor as well as attitudes of clients ${ }^{(12)}$. So, the nurses as providers have many responsibilities in providing these services. The discussion of this study results will be presented under five major concepts: nurses' performance during initial assessment, nurses' performance during general counseling, nurses' performance in assist IUD insertion, nurses' performance in infection control and prevention and nurses' performance at follow up visit.

Concerning total score of nurse's performances, the results of the present study revealed that approximately three quarter of study nurses had fair total score of performance at family planning clinics, while none of them had poor performance. These results may be attributed to the fact that nurses' qualification in the current study found that three quarters of nurses had nursing diploma, two thirds of them had experience in family planning 20- 30 years of experience.

This result isn't in congruent with the result of two other different studies. This result was first: Al-Homayan, et al. $(2013)^{(13)}$ that evaluate impacts of job performance level on nurses in public sector hospitals, stated that nurse's performance was moderate. Second: with Bayoumy $(2017)^{(14)}$ that had evaluated client's satisfaction regarding nurses' performance in family planning centers in a rural Community these results revealed that most of nurses have satisfactory level of performance.

While, this finding contradicted with the result of two other different studies first: Al-Makhaita, et al. $(2014)^{(15)}$ who perform a studied on Job performance among nurses working in two different health care levels, Eastern Saudi Arabia report that almost half of the study staff nurses' performance was in good level. second: Rahmati $\mathrm{R}$, et al. $(2017)^{(31)}$ who conduct studied about Evaluation of the performance of the health care workers in giving fertility counseling that found $91.6 \%$ of nurses had poor performance.

\section{First concept: nurses' performance in initial visit:}

The present study revealed that all nurses had prepared environment of clinic completely as: ensure good ventilation and cleanness of the clinic that is in agreement with Assaf, et al. (2015) ${ }^{(16)}$ who investigate Quality of Care in Family Planning Services at Health Facilities in Senegal/health) revealed that most of the study FP clinics had the basic infrastructure needed for provision of quality FP services especially with respect to the availability of water supply, cleanliness, separate room for examination, at least one skilled staff. As regarding availability of family planning methods, he found more than four-fifth are available in all setting and family planning facilities (equipment's \&supplies). It is evident that less than three quarters of family planning facilities are completed and efficient at all family planning clinics. This result was not amazing since family planning is a priority program of the Ministry of Health \& Population (MOHP) and a component of the reproductive health package \& essential health care services of the Egyptian Health Sector Program. In addition, it reflects the collaboration of governmental and national organizations with ministry of health and population. This study also in agreement with study done by Tumlinson $(2014)^{(17)}$ to assess the quality of FP services in urban Kenya . It clarified that the study FP clinics had acceptable total quality structure level especially in relation to availability of FP methods, infrastructure and performance guidelines. 
As regarding perceived history taken it was observed that all the nurses emphasis on taken personal, social, history of previously used FP methods and more than three quarter of them taken obstetric history and Approximately one- half of them took Breast feeding history This result isn't incongruent with three studies first study Wakjira (2017) ${ }^{(12)}$ who studied Assessment of Client Satisfaction on Family Planning Services Utilization in Wonji Hospital, Ethiopia, 2016 who found that the nurse asking contraceptive method history (95\%) and asking Last Menstrual period (LMP) 77\%. Second studied Tafese et al. (2013) ${ }^{(18)}$ who studied Quality of Family Planning Services in Primary Health Centers of Jimma Zone, Southwest Ethiopia that found $58.7 \%$ of nurses asked the history of contraceptive method used, LMP (75.3\%). Third Elshazly, Tolba (2018) ${ }^{(19)}$ that investigated Family planning counseling sessions in primary healthcare facilities in Sadat City District, Menoufia Governorate that found $54 \%$ of nurses ask about breast feeding.

Regarding assisting in physical examination, it was observed that all of nurses didn't perform measuring of vital signs except blood pressure $90 \%$ measured correct, less than three -fifth measured weight, all of them neglect assistance in physical examinations This result isn't incongruent with two researches; first, Wakjira $(2017)^{(12)}$ who found that $(81 \%)$ of nurses taking blood pressure, weight. Second, Assaf et al. (2015) ${ }^{(16)}$ explored that all the study FP clinics had low process attributes quality especially physical examination contradict with Tafese et al. $(2013)^{(18)}$ who found that $(54.7 \%)$ of nurses assist in physical examination.

\section{Second concept: nurses' performance in counseling:}

Concerning family planning counseling, it was noticed that the great majority of nurses didn't apply the guidelines of counseling completely and they need more training. The present study revealed that the vast majority of nurses asked the client about the preferred method, more than one-half didn't tell the client about different birth spacing methods. less than two-thirds didn't help the client to choose the best method, approximately all of them didn't explain to them method of chosen but they determined the date of return visit correct and complete. This was not amazing since the majority of nurses' diploma in education, in addition to more than one -half not attend of workshops about counseling. This finding is in harmony with three researches; first, Tafese et al. $(2013)^{(18)}$ who found that $93.3 \%$ of the provider informed the clients about modern family planning and of the clients helped to select their preferences to particular methods. This indicates most of the family planning providers are not consistently working as per the guideline which in turn the quality of family planning services. Second, Wakjira $(2017)^{(12)}$ explored that the study FP clinics had poor performance mainly with respect to counseling a and physical care. Third, Tafese et al. $(2013)^{(18)}$ reported that all the study FP clinics had unsatisfactory total process quality especially in terms of the technical competency of the providers. They clarified that the study FP staff had poor performance not only in counseling but also in physical examination and assessment of client's data.

Third concept: nurses' performance in assist in IUD insertion:

For more than 30 years, women throughout the world have been using the intrauterine device (IUD) as their method of contraception. According to Egypt demographic health survey (EDHS) 2014, IUD is the most widely used family method among $30 \%$ of the Egyptian women ${ }^{(20)}$.

The present study revealed that the great majority of nurses didn't apply the guidelines of assistance in IUD insertion completely they had sterilized the instruments and prepared equipment's, recorded the client data, ensured client privacy, inserted the used instruments in 
antiseptic solution and registered date of insertion in the client's record and given her special card correct and complete. In addition, more than two-thirds worn gloves but they neglected assistance during insertion except one-quarter of them assisted the provider during the steps of IUD insertion On the other hand, four-fifth of them didn't give counseling about IUD, didn't explain the procedure, or told the client the expects discomfort during some of the steps In addition, less than four-fifth of them didn't give the client the post insertion instructions of IUD.

This finding is in harmony with four studies; first, Nasr \& Hassan $(2015)^{(21)}$ who found that all nurses prepared availability of the family planning facilities at the clinic and maintain of privacy, prepared sterile instrument and also supported by second, Hutchinson \& Agha (2011) ${ }^{(22)}$ who studied client satisfaction and the quality of family planning services: A comparative analysis of public and private health facilities in Tanzania, Kenya and Ghana that found $92.0 \%$ of nurses maintain quality in visual privacy during examination $97.1 \%$, auditory privacy during examination $96.7 \%$. Third, Wakjira $(2017)^{(12)}$ who found that clients were examined and IUD was inserted for them by family planning services providers. Techniques of providers were observed while they were doing pelvic examination ten clients were informed about the procedure. Providers were washed their hands before and after the procedure while they were examining 12 clients. Sterile techniques were maintained. Fourth, Mohammed (2009) ${ }^{(23)}$ who investigated quality of reproductive health services at primary health centers in an urban area of Iran emphasis on family planning that found the performance in some steps of procedure low as explain insertion procedure to the client (4 of 41) and assisted in pelvic examination before insertion ( 2 of 10 ) hand washing not done in all cases and used instrument placed in antiseptic solution in most of cases.

\section{Fourth concept: nurses' performance in infection prevention and control:}

Infection prevention and control standards become an integral part of the accreditation program for all medical settings in Egypt and patient safety programs, where the National Guidelines for Infection Control" (NGIC) are produced and established by the infection control team at the Ministry of Health \& Population (MOHAP). Eskander, Morsy, Elfeky (2013), Royal College of Nursing $(2017)^{(24,25) \text {. }}$

Concerning of performance of nurses in infection prevention and control practices the result of study revealed that less than three-fifth of study nurses didn't wash their hand correctly. Approximately all of them taken safety precaution during injection correct and complete. More than four-five of them followed recommendation of cleansing and disinfection of equipment correct but incomplete and less than three-fifth of the study nurses follow all recommendation of sterilization of instrument correct and complete. This may be related to $18.6 \%$ only of study nurses attended workshops about infection control precautions.

This finding is in harmony with four researches. First, Kandel $(2014)^{(26)}$ studied nurses compliance with infection control guidelines at governmental maternity hospitals in Alexandria. He found that the majority of nurses don't comply with recommendation of hand washing technique as $66.36 \%$ of them didn't -compliancy to cleans under fingernail and 91.82 use safety precaution during injection. Second, AlKerity \& Naji $(2017)^{(27)}$ who studied Evaluation of Healthcare workers' Practices Concerning Infection Control Measures at Primary Health Care Centers that found the results of health care workers practices concerning the hand hygiene that there was moderate level of score for most items, While the aseptic technique was high level of score for most items.

Third, Tahseen (2014) $)^{(28)}$ who evaluated of nurses, knowledge and practices concerning infection control at primary health 
care centers in Al-Ameriya city who found. That the most of the study nurses had a moderate significant score for most items concerning hand washing, while high significant scores for most items concerning aseptic technique and cleaning. Fourth, Sayed, Elgzar, Ibrahim $(2018)^{(29)}$ studied quality of family planning services in maternal and child health care centers in Damanhur city found $88 \%$ of nurses had moderate level of quality in standard precaution of infection control.

\section{Fifth concept: nurses' performance in follow up:}

Concerning of performance of nurses in follow up the result of study revealed that the vast majority of nurses neglect measuring vital signs and weight of client in the return visit. Approximately all of them renewal of supplies of contraceptive methods and determined the date of next visit and registered correct and complete information in client card, and revised the amounts of stock and types of contraceptive methods and prepared request for getting contraceptive methods from storage. About two-thirds of them prepared periodic reports about stock of contraceptive methods in the clinic. Respectively on the other documentation less than three-fifth of them were not prepare monthly report and quarter year report about clinic activity. This result agreement with four researches; first, Nasr\& Hassan $(2015)^{(21)}$ who found About $90 \%$ of nurses perform family planning data management, logistics and supplies in all family planning clinics. Second, this finding is in line with USAID, (2009) $)^{(30)}$ which found that all family planning service delivery points had monthly family planning logistics and supplies due to supervisory visits on the family planning clinics. Third, Sayed, Elgzar, Ibrahim $(2018)^{(29)}$ who found that $66.7 \%$ of study nurses has high quality data and logistics management documents. Fourth, Bayoumy $(2017)^{(14)}$ who found that had evaluated client's satisfaction regarding nurses' performance in family planning centers in a rural Community this results revealed that three- fourth of nurses has satisfactory level in performance in return or follow up visit.

Finally, the present study denotes that there was a statistically significant relation positive correlation between attending training programs about family planning and level of nurses' performance $(\mathrm{MCP}=0.008$, $\mathrm{FEP}=1.000$ ). No statistically significant between nurses' performance and socio demographic characteristics as: age, marital status, level of education and occupation of the study result agreement with Bayoumy $(2017)^{(14)}$ who found that positive statistically significant between nurses' performance and attending course in your field, year of experience and no statistically significant between nurses' performance and socio demographic characteristics as: marital status, qualification and occupation with $\mathrm{p}$-value $(>0.05)$.

\section{Conclusion}

In all study settings the majority of nurses have fair in total level of performance, while the rest $6 \%$ of the study nurses had good score of performance and none of them had poor score of performance in family planning clinics in addition to nurse's performance have positive significant relation between received training programs about family planning and level of performance in family planning.

\section{Recommendations}

Based on the findings of the present study, the following recommendations are suggested:

- Clear job description should be made for nurses in family planning clinics and review regularly and update as necessary.

- There is an urgent need to design periodic educational training programs to improve knowledge, skills of nurses about family planning care as well as to improve their performance.

- Hospital infection control committee need to pay more attention to frequency and quality of preservice and in-service training programs.

For further researches:

- Replication of the same study in different Egyptian governorates especially rural and Upper Egypt to compare and validate the present study findings.

- Investigate barriers against nurse's compliance with guidelines in initial and return visit in family planning clinics.

- Assess the client satisfaction with quality of nursing care in family planning clinics. 


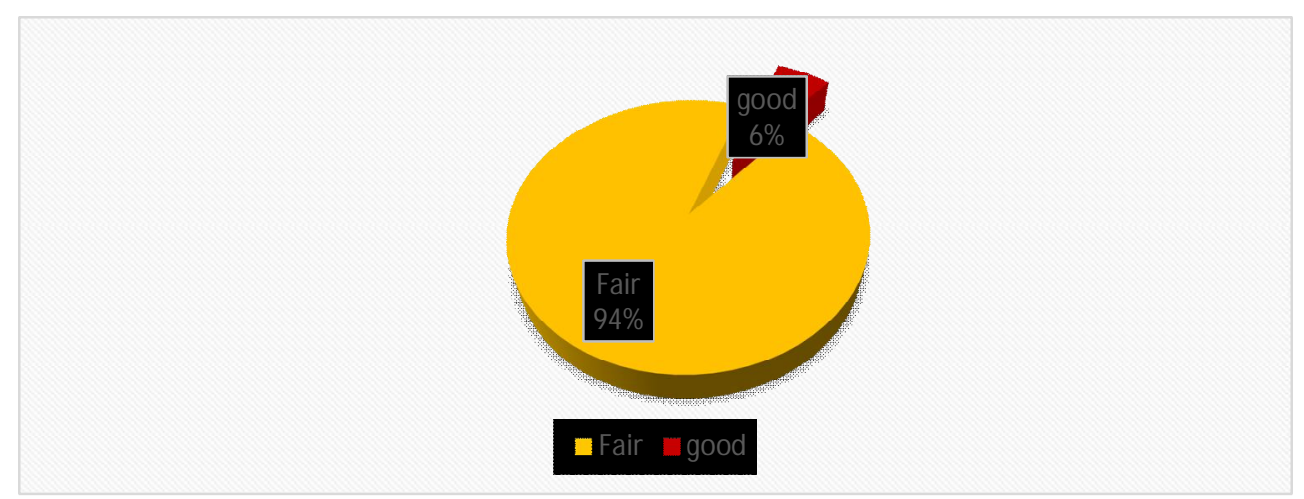

Figure (1): Percent distribution of the study nurses according to total score of nurses' performance

Table (1): Number and percent distribution of the study nurses according to their role during initial assessment

\begin{tabular}{|c|c|c|c|c|c|c|}
\hline \multirow{3}{*}{ Initial Assessment } & \multicolumn{6}{|c|}{$(\mathbf{n}=\mathbf{1 0 0})$} \\
\hline & \multicolumn{2}{|c|}{ Done correct } & \multicolumn{2}{|c|}{$\begin{array}{c}\text { Correct \& } \\
\text { incompletely done }\end{array}$} & \multicolumn{2}{|c|}{ Not done } \\
\hline & No. & $\%$ & No. & $\%$ & No. & $\%$ \\
\hline \multicolumn{7}{|l|}{ 1- Prepare the environment } \\
\hline Ensure good ventilation and cleanness of the clinic & 100 & 100.0 & 0 & 0.0 & 0 & 0.0 \\
\hline Prepare visual aids facilities & 70 & 70.0 & 28 & 28.0 & 2 & 2.0 \\
\hline Prepare available contraceptive methods & 87 & 87.0 & 13 & 13.0 & 0 & 0.0 \\
\hline $\begin{array}{l}\text { Ensure the availability and efficiency of } \\
\text { equipment's }\end{array}$ & 100 & 100.0 & 0 & 0.0 & 0 & 0.0 \\
\hline Ensure the availability of supplies & 100 & 100.0 & 0 & 0.0 & 0 & 0.0 \\
\hline \multicolumn{7}{|l|}{2 - Welcome the client } \\
\hline Greeting the client and determine her needs & 100 & 100.0 & 0 & 0.0 & 0 & 0.0 \\
\hline Create family file for every client & 36 & 36.0 & 4 & 4.0 & 60 & 60.0 \\
\hline \multicolumn{7}{|l|}{ 3- Taking history } \\
\hline Personal and social history & 100 & 100.0 & 0 & 0.0 & 0 & 0.0 \\
\hline Family history & 70 & 70.0 & 10 & 10.0 & 20 & 20.0 \\
\hline Medical and surgical & 48 & 48.0 & 50 & 50.0 & 2 & 2.0 \\
\hline Obstetric history & 76 & 76.0 & 23 & 23.0 & 1 & 1.0 \\
\hline Gynecological history & 43 & 43.0 & 28 & 28.0 & 29 & 29.0 \\
\hline Previously used FP methods & 90 & 90.0 & 7 & 7.0 & 3 & 3.0 \\
\hline Breast feeding & 28 & 28.0 & 23 & 23.0 & 49 & 49.0 \\
\hline \multicolumn{7}{|l|}{4 - Assist in physical examination } \\
\hline \multicolumn{7}{|l|}{\begin{tabular}{|l|} 
A - Take vital signs: \\
\end{tabular}} \\
\hline Measuring temperature & 0 & 0.0 & 1 & 1.0 & 99 & 99.0 \\
\hline Counting pulse & 0 & 0.0 & 0 & 0.0 & 100 & 100.0 \\
\hline Counting respiration & 0 & 0.0 & 0 & 0.0 & 100 & 100.0 \\
\hline Measuring of blood pressure & 90 & 90.0 & 3 & 3.0 & 7 & 7.0 \\
\hline B - Measuring weight & 57 & 57.0 & 9 & 9.0 & 34 & 34.0 \\
\hline C- Measuring height & 0 & 0.0 & 1 & 1.0 & 99 & 99.0 \\
\hline \multicolumn{7}{|l|}{ D- general examination from head to toes } \\
\hline Inspection of face & 0 & 0.0 & 4 & 4.0 & 96 & 96.0 \\
\hline Palpation of thyroid gland & 0 & 0.0 & 0 & 0.0 & 100 & 100.0 \\
\hline Assist in auscultation of heart sound & 0 & 0.0 & 0 & 0.0 & 100 & 100.0 \\
\hline Assist in palpation of abdomen & 0 & 0.0 & 0 & 0.0 & 100 & 100.0 \\
\hline Inspection/palpation of lower extremities & 0 & 0.0 & 0 & 0.0 & 100 & 100.0 \\
\hline
\end{tabular}


Table (2): Number and percent distribution of the study nurses according to their role in counseling session

\begin{tabular}{|c|c|c|c|c|c|c|}
\hline \multirow{3}{*}{ General Counseling } & \multicolumn{6}{|c|}{$\mathbf{n}=\mathbf{1 0 0}$} \\
\hline & \multicolumn{2}{|c|}{$\begin{array}{c}\text { Correct \& } \\
\text { completely done }\end{array}$} & \multicolumn{2}{|c|}{$\begin{array}{l}\text { Correct \& } \\
\text { completely done }\end{array}$} & \multicolumn{2}{|c|}{ Not done } \\
\hline & No. & No. & No. & $\%$ & No. & $\%$ \\
\hline Ask the client about method of her interest & 99 & 99 & 1 & 1.0 & 0 & 0.0 \\
\hline $\begin{array}{l}\text { Tell The client about different Birth spacing } \\
\text { methods as (IUD, Pills and hormonal injection) }\end{array}$ & 35 & 35 & 11 & 11.0 & 54 & 54.0 \\
\hline Help the client to choose the best method for her. & 19 & 19 & 19 & 19.0 & 62 & 62.0 \\
\hline $\begin{array}{l}\text { Explain to her (Mode of action, how to use, } \\
\text { Advantages, Potential side effect, Back-up } \\
\text { method) }\end{array}$ & 0 & 0 & 2 & 2.0 & 98 & 98.0 \\
\hline Determine the date of return visit & 92 & 92 & 8 & 8.0 & 0 & 0.0 \\
\hline
\end{tabular}

Table (3): Number and percent distribution of the study nurses according to their role in IUD insertion

\begin{tabular}{|c|c|c|c|c|c|c|}
\hline \multirow[t]{3}{*}{ Assisting in IUD insertion } & \multicolumn{6}{|c|}{$\mathrm{n}=\mathbf{1 0 0}$} \\
\hline & \multicolumn{2}{|c|}{$\begin{array}{c}\text { Correct \& } \\
\text { completely done }\end{array}$} & \multicolumn{2}{|c|}{$\begin{array}{c}\text { Correct \& } \\
\text { incompletely } \\
\text { done }\end{array}$} & \multicolumn{2}{|c|}{ Not done } \\
\hline & No. & $\%$ & No. & $\%$ & No. & $\%$ \\
\hline $\begin{array}{l}\text { Before insertion: } \\
\text { Sterilize the instruments for insertion. }\end{array}$ & 100 & 100.0 & 0 & 0.0 & 0 & 0.0 \\
\hline Prepare equipment's. & 100 & 100.0 & 0 & 0.0 & 0 & 0.0 \\
\hline Counseling the client, the before IUD insertion. & 14 & 14.0 & 4 & 4.0 & 82 & 82.0 \\
\hline Register all information in the client's record & 99 & 99.0 & 1 & 1.0 & 0 & 0.0 \\
\hline Ask client to empty the bladder before the procedure. & 5 & 5.0 & 6 & 6.0 & 89 & 89.0 \\
\hline Ensure privacy for the client. & 95 & 95.0 & 3 & 3.0 & 2 & 2.0 \\
\hline Assist her to lie in the proper position and drape her. & 44 & 44.0 & 13 & 13.0 & 43 & 43.0 \\
\hline Fix the light source in place. & 95 & 95.0 & 5 & 5.0 & 0 & 0.0 \\
\hline Wash her hands & 14 & 14.0 & 11 & 11.0 & 75 & 75.0 \\
\hline Wear clean gloves & 66 & 66.0 & 6 & 6.0 & 28 & 28.0 \\
\hline $\begin{array}{l}\text { During insertion: } \\
\text { Report to the provider the results of general physical } \\
\text { examination }\end{array}$ & 0 & 0.0 & 0 & 0.0 & 100 & 100.0 \\
\hline Assist in assessment of client's genitalia & 0 & 0.0 & 0 & 0.0 & 100 & 100.0 \\
\hline Assist the provider during the steps of loop insertion & 27 & 27.0 & 7 & 7.0 & 66 & 66.0 \\
\hline $\begin{array}{l}\text { After insertion: } \\
\text { Ask client to wait in clinic for } 15 \text { minutes after } \\
\text { insertion }\end{array}$ & 7 & 7.0 & 12 & 12.0 & 81 & 81.0 \\
\hline Immerse the used instruments in antiseptic solution & 98 & 98.0 & 2 & 2.0 & 0 & 0.0 \\
\hline Remove the gloves and Wash her hands & 50 & 50.0 & 19 & 19.0 & 31 & 31.0 \\
\hline Give the client the post insertion instructions of IUD & 11 & 11.0 & 10 & 10.0 & 79 & 79.0 \\
\hline $\begin{array}{l}\text { Register date of insertion in the client's record and } \\
\text { give her special card }\end{array}$ & 92 & 92.0 & 8 & 8.0 & 0 & 0.0 \\
\hline
\end{tabular}


Table (4): Number and percent distribution of the study nurses according to their role in infection prevention and control in FP room

\begin{tabular}{|c|c|c|c|c|c|c|}
\hline \multirow{3}{*}{ Infection prevention and control } & \multicolumn{6}{|c|}{$(\mathrm{n}=100)$} \\
\hline & \multicolumn{2}{|c|}{$\begin{array}{l}\text { Correct \& } \\
\text { completely done }\end{array}$} & \multicolumn{2}{|c|}{$\begin{array}{c}\text { Correct \& } \\
\text { incompletely } \\
\text { done }\end{array}$} & \multicolumn{2}{|c|}{ Not done } \\
\hline & No. & $\%$ & No. & $\%$ & No. & $\%$ \\
\hline \multicolumn{7}{|l|}{ 1-Hand washing } \\
\hline -Remove Jewelry. & 16 & 16.0 & 26 & 26.0 & 58 & 58.0 \\
\hline -Wet hands with running water. & 100 & 100.0 & 0 & 0.0 & 0 & 0.0 \\
\hline $\begin{array}{l}\text {-Dispense about } 5 \mathrm{ml} \text { of liquid soap or disinfectant into the } \\
\text { palm of the hand. }\end{array}$ & 100 & 100.0 & 0 & 0.0 & 0 & 0.0 \\
\hline -Rub hands palm to palm. & 99 & 99.0 & 1 & 1.0 & 0 & 0.0 \\
\hline $\begin{array}{l}\text {-Rub right palm over left dorsum with interlace fingers } \\
\text { vice versa. }\end{array}$ & 7 & 7.0 & 18 & 18.0 & 75 & 75.0 \\
\hline $\begin{array}{l}\text { - Rub palm to palm with interlace fingers vice versa back } \\
\text { of fingers to opposing palm with fingers interlocked. }\end{array}$ & 2 & 2.0 & 15 & 15.0 & 83 & 83.0 \\
\hline $\begin{array}{l}\text { - Rotational rubbing of left thumb clasped of right palm } \\
\text { vice versa. }\end{array}$ & 0 & 0.0 & 1 & 1.0 & 99 & 99.0 \\
\hline \begin{tabular}{|l}
-Rotational rubbing backward and forward to clasped \\
finger of right hand in left palm vice versa.
\end{tabular} & 0 & 0.0 & 0 & 0.0 & 100 & 100.0 \\
\hline -Rinse hand with clean water. & 98 & 98.0 & 2 & 2.0 & 0 & 0.0 \\
\hline \begin{tabular}{|l}
-Dry hand with towel \\
\end{tabular} & 87 & 87.0 & 5 & 5.0 & 8 & 8.0 \\
\hline \multicolumn{7}{|l|}{ 2-Cleaning \& Disinfection of equipment's } \\
\hline -Wear heavy good utility rubber gloves. & 14 & 14.0 & 12 & 12.0 & 74 & 74.0 \\
\hline -Soak the instrument in tab water containing detergent. & 98 & 98.0 & 2 & 2.0 & 0 & 0.0 \\
\hline $\begin{array}{l}\text {-Scrub instrument vigorously using soft brush, detergent } \\
\text { and water. }\end{array}$ & 100 & 100.0 & 0 & 0.0 & 0 & 0.0 \\
\hline -Rinse instrument with clean water. & 100 & 100.0 & 0 & 0.0 & 0 & 0.0 \\
\hline $\begin{array}{l}\text {-Disinfection of equipment by using alcohol } 70 \% \text { or } \\
\text { chlorine } 1000 \text { / million }\end{array}$ & 100 & 100.0 & 0 & 0.0 & 0 & 0.0 \\
\hline \multicolumn{7}{|l|}{ 3- Sterilization of instruments } \\
\hline -Ensure that all instruments clean and dry & 100 & 100.0 & 0 & 0.0 & 0 & 0.0 \\
\hline -Wrap with foil or place them on tray & 41 & 41.0 & 17 & 17.0 & 42 & 42.0 \\
\hline -Place instruments in the oven & 99 & 99.0 & 1 & 1.0 & 0 & 0.0 \\
\hline $\begin{array}{l}\text {-Heat the holding oven temperature 180c for } 30 \text { minutes or } \\
170 \mathrm{c} \text { for one hour }\end{array}$ & 99 & 99.0 & 1 & 1.0 & 0 & 0.0 \\
\hline \multicolumn{7}{|l|}{ 4- Safety precautions taken while giving injection } \\
\hline -Wear gloves. & 7 & 7.0 & 0 & 0.0 & 93 & 93.0 \\
\hline -Use disposable syringes during IM injection & 100 & 100.0 & 2 & 2.0 & 0 & 0.0 \\
\hline -Not recapping needles. & 100 & 100.0 & 0 & 0.0 & 0 & 0.0 \\
\hline -Place needle in puncture resistant sharps box. & 99 & 99.0 & 1 & 1.0 & 0 & 0.0 \\
\hline
\end{tabular}


Table (5): Number and percent distribution of the study nurses about their role in follow up of client at FP clinic

\begin{tabular}{|c|c|c|c|c|c|c|}
\hline \multirow{3}{*}{ Follow up } & \multicolumn{6}{|c|}{$(\mathbf{n}=\mathbf{1 0 0})$} \\
\hline & \multicolumn{2}{|c|}{$\begin{array}{c}\text { Correct \& } \\
\text { completely } \\
\text { done }\end{array}$} & \multicolumn{2}{|c|}{$\begin{array}{c}\text { Correct \& } \\
\text { incompletely } \\
\text { done }\end{array}$} & \multicolumn{2}{|c|}{ Not done } \\
\hline & No. & $\%$ & No. & $\%$ & No. & $\%$ \\
\hline \multicolumn{7}{|l|}{ 1- Return Visit: } \\
\hline \multicolumn{7}{|l|}{ Detection and management of problems: } \\
\hline Take vital signs & 1 & 1.0 & 10 & 10.0 & 89 & 89.0 \\
\hline Measure weight & 2 & 2.0 & 6 & 6.0 & 92 & 92.0 \\
\hline Make referral if needed. & 38 & 38.0 & 23 & 23.0 & 39 & 39.0 \\
\hline Renewal of supplies of contraceptive methods & 99 & 99.0 & 1 & 1.0 & 0 & 0.0 \\
\hline $\begin{array}{l}\text { Determine the date of next visit and register in her } \\
\text { card }\end{array}$ & 100 & 100.0 & 0 & 0.0 & 0 & 0.0 \\
\hline \multicolumn{7}{|l|}{ 2- Follow up for clinic: } \\
\hline $\begin{array}{l}\text { Revise the amounts of the stock and types of } \\
\text { contraceptive methods }\end{array}$ & 100 & 100.0 & 0 & 0.0 & 0 & 0.0 \\
\hline $\begin{array}{l}\text { Prepare request for getting contraceptive methods } \\
\text { from storage. }\end{array}$ & 100 & 100.0 & 0 & 0.0 & 0 & 0.0 \\
\hline \multicolumn{7}{|l|}{ 3- Documentation } \\
\hline Register all client data accurate and careful & 99 & 99.0 & 1 & 1.0 & 0 & 0.0 \\
\hline Keep all records clean and tidy & 93 & 93.0 & 1 & 1.0 & 6 & 6.0 \\
\hline $\begin{array}{l}\text { Take informed consent from client about chosen } \\
\text { methods }\end{array}$ & 8 & 8.0 & 9 & 9.0 & 83 & 83.0 \\
\hline $\begin{array}{l}\text { Prepare periodic reports about stock of } \\
\text { contraceptive methods in the clinic }\end{array}$ & 66 & 66.0 & 5 & 5.0 & 29 & 29.0 \\
\hline $\begin{array}{l}\text { Prepare monthly report and quarter year report } \\
\text { about clinic activity }\end{array}$ & 8 & 8.0 & 34 & 34.0 & 58 & 58.0 \\
\hline
\end{tabular}

Table (6): Relationship between level of nurse's performance and socio demographic characteristics

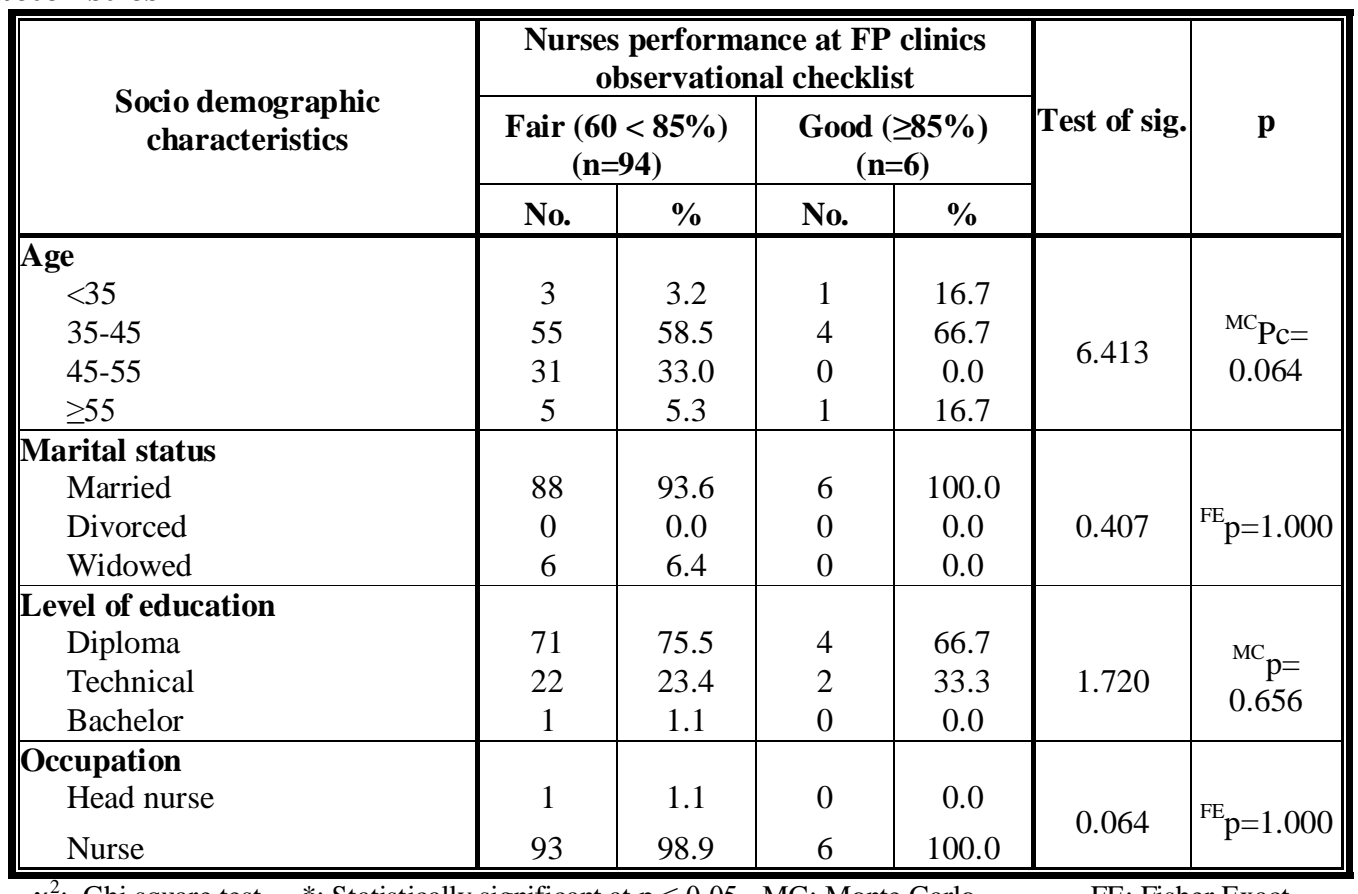

$\chi^{2}$ : Chi square test $*$ : Statistically significant at $\mathrm{p} \leq 0.05 \quad$ MC: Monte Carlo

FE: Fisher Exact 
Table (7): Relationship between level of nurses' performance and participation in family planning programs

\begin{tabular}{|c|c|c|c|c|c|c|}
\hline \multirow{3}{*}{$\begin{array}{c}\text { Participation in family planning } \\
\text { programs }\end{array}$} & \multicolumn{4}{|c|}{$\begin{array}{c}\text { Nurses performance at FP clinics } \\
\text { observational checklist }\end{array}$} & \multirow{3}{*}{ Test of sig. } & \multirow{3}{*}{$\mathbf{p}$} \\
\hline & \multicolumn{2}{|c|}{$\begin{array}{c}\text { Fair } \begin{array}{c}(60<85 \%) \\
(n=94\end{array} \\
\end{array}$} & \multicolumn{2}{|c|}{$\begin{array}{c}\text { Good }(\geq 85 \%) \\
(n=6)\end{array}$} & & \\
\hline & No. & $\%$ & No. & $\%$ & & \\
\hline \multicolumn{7}{|l|}{$\begin{array}{l}\text { Years of experience in nursing } \\
\text { (years) }\end{array}$} \\
\hline$<10$ & 1 & 1.1 & 0 & 0.0 & \multirow{4}{*}{4.930} & \multirow{4}{*}{${ }^{\mathrm{MC}} \mathrm{p}=0.171$} \\
\hline $10-20$ & 16 & 17.0 & 3 & 50.0 & & \\
\hline $20-30$ & 60 & 63.8 & 2 & 33.3 & & \\
\hline$\geq 30$ & 17 & 18.1 & 1 & 16.7 & & \\
\hline \multicolumn{7}{|l|}{$\begin{array}{l}\text { Years of experience in family } \\
\text { planning (years) }\end{array}$} \\
\hline$<10$ & 37 & 39.4 & 3 & 50.0 & \multirow{4}{*}{3.411} & \multirow{4}{*}{${ }^{\mathrm{MC}} \mathrm{p}=0.283$} \\
\hline $10-20$ & 39 & 41.5 & 1 & 16.7 & & \\
\hline $20-30$ & 14 & 14.9 & 1 & 16.7 & & \\
\hline$\geq 30$ & 4 & 4.3 & 1 & 16.7 & & \\
\hline \multicolumn{7}{|l|}{$\begin{array}{l}\text { Attending training program about } \\
\text { family planning: }\end{array}$} \\
\hline Yes & 77 & 81.9 & 5 & 83.3 & $0.008^{*}$ & ${ }^{\mathrm{FE}} \mathrm{p}=1.000$ \\
\hline No & 17 & 18.1 & 1 & 16.7 & & \\
\hline \multicolumn{7}{|l|}{$\begin{array}{l}\text { If yes: number of training program } \\
\text { attended in family planning: } \\
(\mathrm{n}=82)\end{array}$} \\
\hline 1 & 17 & 22.1 & 2 & 40.0 & \multirow{4}{*}{3.635} & \multirow{4}{*}{$\begin{array}{l}{ }^{\mathrm{MC}} \mathrm{p}= \\
0.230\end{array}$} \\
\hline 2 & 40 & 51.9 & 2 & 40.0 & & \\
\hline 3 & 16 & 20.8 & 0 & 0.0 & & \\
\hline 4 & 4 & 5.2 & 1 & 20.0 & & \\
\hline \multirow{6}{*}{$\begin{array}{l}\text { Name of training program attending } \\
\text { Counselling } \\
\text { Infection control } \\
\text { Documentation } \\
\text { Basic of nurse in family planning } \\
\text { Family planning methods } \\
\end{array}$} & & & \multirow{6}{*}{$\begin{array}{l}4 \\
0 \\
2 \\
2\end{array}$} & & & \multirow{6}{*}{$\begin{array}{l}\mathrm{FE}_{\mathrm{p}}=0.323 \\
\mathrm{FE}_{\mathrm{p}}=0.153 \\
\mathrm{FE}_{\mathrm{p}}=0.650 \\
\mathrm{FE}_{\mathrm{p}}=0.225 \\
\mathrm{FE}_{\mathrm{p}}=0.200\end{array}$} \\
\hline & 72 & 93.5 & & 80.0 & 1.263 & \\
\hline & 30 & 39.0 & & 0.0 & 3.072 & \\
\hline & 24 & 31.2 & & 40.0 & 0.169 & \\
\hline & 13 & 16.9 & & 40.0 & 1.679 & \\
\hline & 12 & 15.6 & & 40.0 & 1.977 & \\
\hline
\end{tabular}

$$
\chi^{2} \text { : Chi square test MC: Monte Carlo FE: Fisher Exact }
$$




\section{References}

1. Argago T, Hajito K, Kitila S. Client satisfaction with family planning services and associated factors among family planning users in Hossana town public health facilites, South Ethiopia: Facility based cross sectional study. International journal of nursing and midwifery.2015;7(5) 74-83.

2. United Nations. United Nations, Department of Economic, and Social Affairs. World. Available at: http:///www.Worldometers.info/worldpopulation. Retrieved On: 5 November 2017.

3. Eltomy E, Saboula N, Hussein A. Barriers affecting utilization of family planning services among rural Egyptian women. EMH J.2013; 19(5):400-8.

4. El-Shazly H, Elkilani O, Nashat N. Evaluation of family planning services in a rural area in Al-Shohdaa district, Menoufiya governorate. University, Menoufia Medical Journal .2015; 28:6506.

5. Smith R, Ashford L, Gribble J, Clifton D. Family Planning Saves Lives, 4th edition. Washington, DC. 2009.

6. Starbird E, Norton M, Marcus R. Investing in Family Planning: Key to Achieving the Sustainable Development Goals. Global health, science and practice.2016; 4(2), 191-210.

7. Stover J, Ross J. How increased contraceptive use has reduced maternal mortality. Maternal and child health journal.2010; 14(5), 687-95.

8. Mahamed K, Abrha A, Liben M, Shamie R. Modern family planning methods utilization and associated factors among female students in Aysaita town, northeastern Ethiopia. Medico Research Chronicles. 2017; 4 :411-19.

9. Tesfaye T, Abera A, Balcha F, Nemera G, Belina $S$.Assessment of factors affecting performance of nurses working at Jimma university specialized hospital in Jimma town, Oromia Region, South-West Ethiopia. J Nurs. 2015; 4:312.

10. Awases H, Bezuidenhout C, Roos H.Factors affecting the performance of professional nurses in Namibia', AOSIS Open Journals Curationis .2013; 36(1).

11. Nikpeyma N,Saeed Z ,Azargashb E. Majd H. Problems of Clinical Nurse Performance

Appraisal System: a qualitative Study. Asian Nursing Research. 2013;8 15-22.

12. Wakjira A. Assessment of Client Satisfaction on Family Planning Services Utilization in Wonji Hospital, Ethiopia, JBR Journal of Clinical Diagnosis and Research .2017; 5(1).

13. Al-Homayan M, Shamsudin M, Subramaniam C, Islam R. Impacts of job performance level on nurses in public sector hospitals. American Journal of Applied Science, 2013;10(9)1115-23.

14. Bayoumy G. Client's satisfaction regarding nurses' Performance in Family Planning Centers in a Rural Community. published Master Thesis, Faculty of Nursing. Ain Shamis University, 2017.

15. Al-Makhaita M, Sabra A, Hafez A. Job performance among nurses working in two different health care levels, Eastern Saudi Arabia: a comparative study. International Journal of Medical Science and Public Health, 2014;3 (7) 832-7

16. Assaf S, Wang W, Mallick L. Quality of Care in Family Planning Services at Health Facilities in Senegal. DHS Analytical Studies. Rockville, Maryland, 2015; 55.

17. Tumlinson K. Measuring the quality of family planning service delivery in urban Kenya. Published dissertation. University of North Carolina, 2014. Available at: https://cdr. lib.unc. Edu/ index able content/urid: Retrieved on15/5, 2017.

18. Tafese F, Woldie M, Megerssa B.Quality of Family Planning Services in Primary Health Centers of Jimma Zone, Southwest Ethiopia. Ethiop J Health Sci., (2013); 23(3): 245-54.

19. Elshazly H, Tolba E, Elhady N. Family planning counseling sessions in primary healthcare facilities in Sadat City District, Menoufia Governorate. Menoufia Medical Journal, 2018;31:613-8.

20. El-Zanaty F. Egypt Demographic and Health Survey. Cairo, Egypt: Ministry of Health and Population. El-Zanaty and Associates, National Population Council, 2014; 11-2.

21. Nasr E, Hassan H. Association between quality of family planning services and client's satisfaction level in maternal and child health centers in Port Said city. Journal of Nursing Education and Practice, 2016; 6(1), 85-99. 
22. Hutchinson M, Agha S. Measuring client satisfaction and the quality of family planning services: A comparative analysis of public and private health facilities in Tanzania, Kenya and Ghana, BMC Health Services Research, 2011;11(203).

23. Mohammed S. Quality of reproductive health services at primary health centers in an urban area of Iran. Karolinska. Institution. Stockholm, Sweden. 2009.

24. Eskander H, Morsy W, Elfeky H. Intensive Care Nurses' Knowledge \& Practices regarding Infection Control Standard Precautions at a Selected Egyptian Cancer Hospital. Journal of Education and Practice, 2013; 4 (19).

25. Royal College of Nursing Essential Practice for Infection Prevention and Control. London. Royal College of Nursing, 2017.

26. Kandel E. Nurses complience with infection control guidelinerss at governmental maternity hospital in Alexandria. Unpublished Master Thesis, Faculty of Nursing. Alexandria University, 2014.

27. Al-Kerity S, Naji A. Evaluation of Healthcare workers' Practices Concerning Infection Control Measures at Primary Health Care Centers". Sci. J. Med. Res, 2017; 1 (2): 63-8.
28. Tahseen A. Evaluation of nurses, knowledge and practices concerning infection control at primary health care centers in Al-Amara city. Master Thesis, University of Baghdad College of Nursing, 2014; pp 52-72.

29. Sayed S, Elgzar W, Ibrahim H .Quality of family planning services in maternal and child health care centers in Damanhur city. International Journal of Studies in Nursing, 2018; 3 (2).

30. U.S. Agency for International Development (USAID). Contraceptive Logistics Management system assessment report, Nigeria. (2009) Available at : URL: http:// www .Nigeria. unfpa. org/ pdf/ ng cont logimanaasse Retrieved on:15/2/2019.

31. Rahmati R, Khadivzadeh $T$, Esmaily $H$, Bahrami H. Evaluation of the Performance of the Health Care Workers in giving consultation about the fertility promotion. Journal of Midwifery and Reproductive Health, 2017; 5 (2): 911- 8.

32. Ministry of health child survival project. USAZD. National maternal mortality study, Cairo, 2010. 